list; all of these proved fatal. Violent or active delirium was also invariably fatal. Cyanosis was a sign of grave import, only I case of 5 in which it occurred recovering. Hiccough occurred before death in 2 fatal cases. It did not necessarily prove the presence of peritonitis. Thin watery offensive stools were observed in I case with similar termination. Of 27 patients with a temperature reaching $105^{\circ} \mathrm{F}$., ro died (40 per cent.); 2 in whom $106^{\circ} \mathrm{F}$. was reached, both succumbed. On the other hand, a pulse of over 140 persisted for days and yet recovery took place. Among cases in which hæmorrhage from the bowel occurred the mortality, as before mentioned, was 28.5 per cent., as against a total percentage mortality of 18.5 per cent. Only I case was directly fatal, but this complication evidently increases the gravity of the outlook. Floccitation and carphology were not incompatible with a favourable termination, nor was pregnancy a bar to recovery. Absence of delirium was not always a good sign, at least I severe and fatal case being accompanied by clearness of mind throughout.

Treatment.

As a rule, treatment was expectant and consisted of liquid diet, absolute rest, and attention to symptoms. The routine medicine was dilute hydrochloric acid, with syrup of orange and water. Excessive fever was treated by tepid, cold, or iced sponging. Ice-cradling was also employed with less visible benefit. One case treated by raising the bed clothes on a cradle away from the patient died of double pneumonia. Antipyretic drugs were not frequently used, with the exception of quinine, which appeared beneficial in some cases. Of aniiseptics, turpentine was most frequently relied upon, and was taken well in most instances. The same cannot be said of naphthalene, which frequently caused sickness. In at least one case the pills in which it was contained were persistently passed in the motions unaltered. Antityphoid serum was used in a few cases without visible effect. In I of these cases a relapse subsequently occurred.

APPENDIX of CASES.
CASE t. Meningitis.-S. W., male, aged ro, admitted, under Dr. Green, May 25 th, 1892. TIJ illness had begun suddenly on May roth, with head"che, pain in the abdomen. and diarrluea. The child's temperature on admission was ro4 $6^{\circ} \mathrm{F}$., and fell gradually for the next, ten days, reaching normal on the twenty-fourth day of the illness. The main symptoms throughout were continual vomiting and obstinate constipation. The abdomen at first was retracted, but the liver was apparently enlarged and
reached nearly down to the umbilicus. Later on the abdomen became reached nearly down to the umbilicus. Later on the abdomen became
somewhat distended. The patient wandered mentally at first, but this condition gradually improved. Death took place on the forty-fifth day. three weeks after the temperature had reached normal. The diagnosis had in the first instance been typhoid fever : later a suspicion of tuberculous peritonitis was entertained.

Post mortem there were found old healing typhoid lesions of the small intestine in the neighbourhood of the ileo-cecal valve, with simple cerebral meningitis. The spleen was normal. There was a congenital hernia the liver.

CASE 1I. Early Thrombosis: Peripheral Neuritis.-E. B., female, aged 22, servant, admitted under Dr. Green, September 2 ist, 1895. The disease began on September ${ }_{15}$ th with shivering. On admission there was pain and tenderness in the left groin, and a distinct venous cord could be felt in the upper part of the thigh. There was cedcma of the leg. The urine contained a consider'able quantity of albumen. The temperature at its highest reaclied $104.6^{\circ}$; ; twenty-tourth day. On the cleventh day the patient complained of pain in the legs, but no cause beyond the thrombosis, which was gradually clearing up, was found. On the fourteenth day she brought up blood twice in voniting, and a slight hemorrhage from the bowel occurred on the twenty-first day. Three dass later slight desquamat on was noticed on the abdomen, palms, and soles. On the twenty-ninth day a rearudescence occurred. On October roth (thirty-first day) pain was complained of in the hands and fcet. and the knee-jerks were found to be absent. On the ally passed off, and the temperature became finally normal on the fortyfirst day. The patient was severely ill both in the first attack and the recrudescence; in the latter the pulse for days was over 140 , reaching ${ }_{152}$ beats to the minute on one occasion.

CASE III. Paralysis of Left Foot.-R. B., a boy aged 12, was admitted on October r th, r895, under Dr. Abercrombie. on the eiglith day of the disease. He then suffered from lieadache, and was irritable but not delirious. No typical spots were then found. Tâthe cérébrale could be obtained Two days later he was delirious, and tonk his food with great reluctance. There was fairly marked bronchitis. Spots appeared on the twelfth day of the disease. On the fifteentl day he was fed by the nasal tube because of the trouble in getting him to take nourishment, and this method of feeding was continued till November 1 , th, the thirty-sixth day of the disease. The patient continued in a curious irritable condition, resenting all interference, and refusing to speak. On Novelnber Irth an erythematous rash appeared on the body and limbs, but passed off rapidly. On November r 13 th a relapse occurred. with pains in the limbs and fresh spots, and more bronchitis a few days later. The patient became much
emaciated, and the mental condition continued. On December is th it was noted that he persisted in biting holes in the sheets. On December 16 th a fresh relapse occurred, after the temperature had been normal for six days, and lasted one week. On January r6th the patient complained of numbress in the left foot, and a sensation of "pins and needles." The knee-jerks were found to be increased, and ankle-clonus could be obcould not move it. A few days later there was considerable tenderness could not move it. A few days later there was considerable tenderness
over this shin, and ankle-clonus had disappeared. The knee-jerks remained brisk till February ist, when some muvement of the toes liad re turned. Gradual improvement then took place. Towards the end of the tulned. Gradual improvement then took place.

CASE Iv. Embolism of Femoral A rtery. -C. M., male, aged ig, blacksmith, was admitted on October 5 th, 1897 , on the eleventh day of the disease under the care of Dr. Green. The onset had been with headache, pains in the back and vomiting. On admission he was suffering from sore throat and dysphagia, and was delirious and restless. The usual rash was seen
on abdomen. Five days after admission (sixteentl day) he was seized on abdomen. Five days after admission (sixteenth day) he was seized with sudden intense pain in the right thigh; the leg was found pale, and
soon became white and cold. Pulsation ceased from the first in the tibial soon became white and cold. Pulsation ceased from the fir'st in the tibial survived the occurrence till October 4 th, signs of gangrene meanwhile appearin.

Post-mortem there was found embolism of the right common iliac artery, with secondary thrombosis. Typhoid ulceration was well marked in both
small and large intestines, and there was an infarct in the right kidney. The spleen weighed $8 \frac{1}{2}$ ozs.

CASE v. Erysipelas. - F. N., male, aged 16, a packer, in October $24-35$, 1898, was admitted under the care of Dr. Bruce on the twelfth day of the disease. Temperature ro $4^{\circ} \mathrm{F}$.; typical rash. Two days later an erythema. tous patch appeared on the nose and neighbouring areas of cheeks. This rapidiy spread to the orbital regions, and involved the whole of both cheeks. Antistreptococcus serum was injected, and the temperature,
which at one time reached $105.4^{\circ}$, fell somewhat. A doubtful presystolic wruit developed over the precordial area. Two further injections of serum were given on following days but the patient did not rally. From the severity of the ioflammation surrounding the orbit, it appeared that had the patient survived, the tissues surrounding the eyes would

sloughed, an apparent line of demarcation being visible on the face.
Post-Mortem Examination.-The Peyer's patches in the small intestine were swollen but not ulcerated, and the large bowel was unaffected. The spleen was much enlarged, weighing $19 \frac{1}{2}$ ounces. Death at this early
stage of the disease was apparently due to the erysipelas and not to the stage of the disease
typhoid infection.

typhoid infection.
CASE vi. Perforation: Jocalised Abscess.-J. T., a kitchenmajd, aged 40. CASE vi. Perforation: Jocalised Abscess.-J. T., a kitchenmajd, aged 40 .
was admitted on July inth under the care of Dr. Abercrombie for swelling was admitted on July i2th under the care of Dr. Abercrombie for swelling of ardomen and pain. At the end of June she had been seized with severe pain in the abdomen and faintness. She took to her bed, and for the next
fortnight was continually sick after all food. On admission she appeared fortnight was continually sick after all food. On admission she appealed of intestine in movement were visible and palpable. The uterine fornices of intestine in movement were visible and palpable. The uterine fornices
were obliterated and the uterus fixed in a hard mass, suggesting maligwere obliterated and the uterus fixed in a hard mass, suggesting malig-
nant disease. An ulcer was found in the rectum apparenty communicatnant disease. An ulcer was found in the rectum apparently ('ommunicatof the patient was remittent, averaging ror ${ }^{\circ} \mathrm{F}$. (103 $3^{\circ}$ to $\left.98.4^{\circ}\right)$. The stools were liquid and contained small quantities of pus. Uperation was advised by Mr. Boyd, and while the patient was under an ancesthetic the size of the cavity was made out to be 2 to 3 inches in diameter. It was irrigated and drained. The patient gradualiy sank.

Post mortem there were found t.ppical typhoid ulcers of the intestine, Post mortem thele were found t.ypical typhoid ningers of the infestine,
both large and sma], some healing, some slonghing. One of these had perforated, giving rise to pelvic abscess, which had subsequeotly burst small intestiue.

Notes.

1 In a recent case acute arthritis occurred, affecting both knees and ankles. Pain was also felt in the shoulders. One knee-joint contained a fair quantity of fluid. The patient, aged is years, cried out if the affected joints were touched. The condition was apparently unafiected by salicylate of soda, and some degree of ankylosis remained during convalescence. ${ }^{2}$ In a recent case a systolic bruit, slightly conducted into the axilla, developed in the course of the disease. It persisted and gave the impression of being pericardial, or at all events exocardial, in nature. 3 In a case still remaining in the hospital diphtheria bacilli were found in the false membrane, which invaded the trachea. Traclieotomy was performed, and the patient now appears convalescent. 4 In a recent case two perforations of the small intestine.

\section{AN UNUSUAL CASE OF CARDIO-PULMONARY RÂLE.}

By JAMES CARSLAW, M.A., M.B , C.M.,

Assistant to Professor of Medicine, Glasgow University ; Extra Dispensary Physician, Western Infirmary, Glasgow.

A patient recently under my care presented a remarkable cardio-pulmonary physical sign.

He was a young nan. aged 21 , a footman, and was first seen by me on April 15th, 1899. His complaint was of cough and spit, with general weakness and "a tickling sound in his throat." He had begun to have cough and spic two months earlier, also pains in the left shoulder and nn the left side of the chest in front. He lad had no hæmoptysis. but had been getting thinner, and had had some undue perspiration at nights. His digestion had kept good, and he could take his fond well. and his bowels were regular. A week or ten days before his first visit to me he first
noticed a clicking sound in his throat when he took a lorg breath, which 
phenomenon continued and was easily demonstrated. It was first noticed when after hurying up the stairs with some luggage he stopped to take a breath. It was still very evident when he passed from my care in the flrst week of May to join his friends in a different part of the country. The patient gave no story of previous pulmonary illness, nor of diarrhoea. He had been a footman for four years, and previously had worked in the North-British Railway engine shop in Edinburgh. His family history was distinctly tuberculous. His father died at the age of 49 from "consumption," after six months' illness. His mother is alive and well at the age of 4r. Of a family of seven, two died in infancy, one of "water in the head," and the other of some intestinal illness. The others are in good lealth.

The patient was of small stature, rather pale and thin. His expectoration was not in large quantity, but mucopurulent, and found on staining to be swarming with tubercle bacilli. Examination of the chest revealed some dulness of the left apex, where the respiratory murmur was sligltly tubular, and accompanied by clicking rales, though there were no definite cavernou signs. Fine crepitating rales were found all through the left lung to the base, but the right lung was healthy. The clicking sound in the throat of which the patient complained was quite distinct, and could be easily induced. When he took a long breath and held his breath there occurred towards the end of the inspiration a clicking sound of musical quality, and synchronous with the beating of the heart. Five or six of these clicks might be got with one respiration. Each click corresponded with one beat of the heart, and could be heard at some considerable distance from the patient without the use of the stethoscope. On careful auscultation this pulsaing sound was heard well at the manubrium and on either side of it, but best over the trachea, though even there as if from a distance. tion of the nouned tion of "current of air on respiration, such as is described under the name of pulse breath." The examinatic

The patient had been taking cod-liver oil and malt extract and to this in the was advised to give up his situation

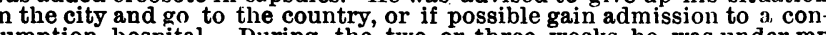
列

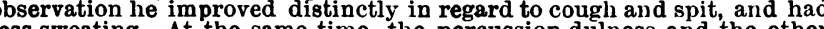
of noticed to be getting less distinct, and not so musical. On Mas noted that on one of the preceding days it had been on fy 2 di was day. In a letter to me, dated May 24th he writes that "his cough is much better, and he spits less too" while"the ticking sound in the throat is now nearly away." An attempt was made by the kindness of Dr. John McIntyre to record the sound on the phonograph; but, unfortunately hy the time this was tried the sound was becoming less distinct, and the attempt was unsuccessful.

Cardio pulmonary murmurs are of considerable rarity, and belong usually to one of two principal groups-either murmurs exactly like cardiac murmurs in quality and rhythm, but dependent on pulmonary, not on cardiac, disease, or simply rhythmic alterations of the respiratory murmur synchronous with the heart's sounds. The former variety usually occurs in advanced cases of phthisis with a large, thin-walled cavity in the neighbourbood of the heart, and its production is somewhat akin to that of the cracked-pot sound. During the systole of the heart some of the air of the cavity is driven out through the bronchus, with which it communicates, producing a murmur, and during the diastole the air is readmitted and a fainter murmur may occur. ${ }^{1}$ Not unlike this is the rhythmic alteration of the respiratory murmur known as "pulse breath," which is also principally associated with airfilled cavities in the lung of considerable size, or with pneumothorax. ${ }^{2}$ However, in certain cases of aneurysm of the thoracic aorta the pulsation. of the sac influences the current of air in the trachea and canses a rhythmic blowing sound, as described by Dr. Drummond, of Newcastle. ${ }^{3}$ A certain amount of this pulsatile respiration can in certain circumstances be demonstrated in healthy persons.

In the case now described, however, there was a cardio-pulmonary sound quite distinct from those already referred to, and $I$ have failed to find any case of the same recorded. The patient is suffering from phthisis, and probably has some excavation in the upper part of his left lung, though there were no definite cavernous signs. His illness was only of two months' duration, and there was certainly no large cavity and no sign of pneumothorax. But at least for a period of four weeks, when he took a long breath there was a series of musical clicks synchronous with the beats of the heart, and the probable explanation of the phenomenon is that there was some cavity in the upper part of the left lung impinged upon by the heart itself or by the aorta, and that the sound was produced by the impact thus received. To produce the musical sounds of cavity the principal physical conditions required are an air-filled cavity of suitable shape, with sufficiently smooth walls, and a proper degree of tension of the walls. In the present case there probably was a suitable cavity, and the necessary degree of tension was got by the patient breathing deeply and holding his breath, and the impinging force was then provided by the action of the heart. This is the view that was taken of the case by Sir William Gairdner, Dr. Finlayson, and others who saw the patient with me.

REFERENCES

1 See a case recorded by Dr. Frederick Taylor in the Transactions of the Clinical Society of Locdon, r88o, vol. Xiil, p. 365. 2 Dr. Finlayson, BRITISF Medical Journal, r88, vol. i, p. 403. 3 Report of the Proceedings of the Northumberland and Durham Medical Society, $1888-89$, p. 158 .

\section{ME MORAN DA: \\ MEDICAL, SURGICAL, OBSTETRICAL, THERA- PEUTICAL, PATHOLOGICAL, ETC.}

ARTERIAL TENSION UNDER AN ASTHETICS. Is the recent discussion at the Society of Anæsthetists reference was made to the vascular tension under various anæsthetics. Dr. Macphail, having to give gas and oxygen for a preliminary examination, and a few days later chloroform to the same patient for an operation, asked me to take pulse tracings of the case.

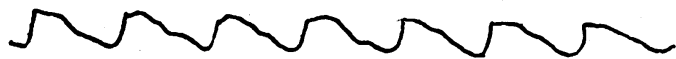

Fig. r; -Normal pulse tracing of the patient.

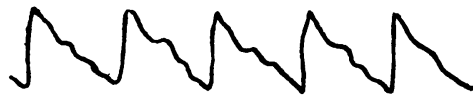

Fig. 2.-Gas and oxygen. Ten minutes.

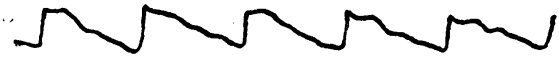

Fig. 3.-Chloroform. Twenty minutes.

As seen by them the patient's normal vascular condition was one of high tension. The gas and oxygen lowered this tension, apparently by dilating the peripheral vessels, since the artery at the wrist became much larger; while chloroform had no effect at all upon the arterial tension. The pulse under the gas and oxygen, owing to the enlarged artery, was more easily felt at the wrist than normally or under the chloroform. This lowering of peripheral resistance by dilating vessels should do good by preserving the heart from strain, but I should think would tend to increase the bleeding during an operation. Brighton.

Walter Broadbent, M.D., M.R.C.P.

CIRCUMCISION UNDER COCAINE.

DURING my last tour in India I performed circumcision over roo times under the influence of this drug, and never gave a general anæsthetic for its performance. Since January last I have done it in this hospital 25 times and have never seen any bad effects.

In every case where there is a sore on the prepuce, or a long prepuce imprisoning a sore, I operate, One grain of cocaine in 20 minims is injected into the prepuce in two places 4 grains in about 2 drachms of water are then injected between the prepuce and glans and kept there by the patient. Very little of this is absorbed. In about ten minutes a piece of drainage tube is tightly tied round the base of the organ and the operation commenced. After the skin and mucous membrane have been removed, the parts are thoroughly washed with $I$ in 1,000 perchloride of mercury solution poured from a bottle. A continuous catgut suture then unites the skin and mucous membrane, and a dry dressing over oiled lint is firmly applied before the ligature is removed. I never tie a vessel, and have never had to remove a dressing on account of hæmorrhage. Even in cases in which a chancre is exposed on the glans I never get infection of the wound, and union by first intention is the rule.

I used eucaine recently in the same manner as cocaine. It produced extensive œdema of the penis, and when the cut surface was washed with the perchloride solution the tissues became very dark, and appeared as if washed with strong solution of permanganate of potash. The parts sloughed where the eucaine had been injected. 